\title{
Steered Molecular Dynamics Simulations of Coumarin2 5Z/5E Pulling Reveal Different Interaction Profiles for Four Human Cytosolic Carbonic Anhydrases
}

\author{
Mustafa TEKPINAR*1
}

1Yüzüncü Yıl Üniversitesi, Fen Fakültesi, Fizik Bölümü, Kampus, Van

(Alınış / Received: 06.12.2017, Kabul / Accepted: 26.03.2018, Online Yayınlanma / Published Online: 27.04.2018)

\section{Keywords}

Steered molecular dynamics, Coumarins,

Rupture force,

Protein-ligand interaction,

Human cytosolic carbonic anhydrases

\begin{abstract}
Carbonic anhydrase (CA) is an important enzyme, which has multiple isoforms each performing different functions in humans. Characterizing the interactions of carbonic anhydrase isoforms with ligands is a difficult but important task. In recent years, steered molecular dynamics (SMD) has been used successfully to characterize ligand binding and unbinding events. In this study, constant velocity SMD simulations were performed on four cytosolic human carbonic anhydrases (carbonic anhydrase I, II, III and VII) using a ligand called Coumarin2 5Z/5E to understand better the nature of interactions between this ligand and the various enzyme isoforms. The influence of force constant and pulling velocity on SMD simulations were investigated. When the force constant and the pulling velocity were changed, no significant effect on interaction profiles was observed. Finally, hydrogen bond interactions, Histidine 64 positions and the differences between force-distance profiles for all isozymes were analyzed. These results demonstrate that human cytosolic carbonic anhydrases I, III, and VII show similar Coumarin2 5Z/5E unbinding patterns with different rupture forces, while carbonic anhydrase II has a distinct interaction profile.
\end{abstract}

\section{Kumarin2 5Z/5E'nin Çekildiği Yönlendirilmiş Moleküler Dinamik Simülasyonları İnsana ait Dört Sitozolik Karbonik Anhidraz için Farklı Etkileşim Profilleri Ortaya Çıkarmaktadır}

\section{Anahtar Kelimeler}

Yönlendirilmiş moleküler dinamik,

Kumarinler,

Kopma kuvveti,

Protein-ligand etkileşimi,

İnsana ait sitozolik karbonik anhidrazlar

\begin{abstract}
Özet: Karbonic anhidraz (CA), insanlarda herbiri farklı fonksiyonlar icra eden çeşitli izoformlara sahip önemli bir enzimdir. Karbonik anhidraz izoformlarının ligandlar ile etkileşimlerini karakterize etmek zor fakat önemli bir iştir. Son yıllarda yönlendirilmiş moleküler dinamik, ligand bağlanma ve kopma olaylarını karakterize etmek için başarıyla kullanılmıştır. Bu çalışmada, Kumarin2 5Z/5E adlı ligandı kullanarak dört sitozolik insan karbonik anhidrazının (karbonik anhidraz I, II, III ve VII) bu ligand ile etkileşimlerinin doğasını anlamak amacıyla sabit hızda yönlendirilmiş moleküler dinamik (YMD) simülasyonları uygulandı. Kuvvet sabitinin ve çekme hızının YMD simülasyonları üzerine etkisi incelendi. Kuvvet sabiti ve çekme hızı değiștirildiği zaman etkileşim profillerinde önemli bir değişim gözlenmedi. Son olarak hidrojen bağı etkileşimleri, Histidin 64 pozisyonları ve kuvvet-mesafe grafikleri tüm isozimler için analiz edildi. Bu sonuçlar, insana ait sitozolik karbonik anhidraz I, III ve VII'nin -farklı kuvvetlerle de olsa- Kumarin2 5E/5Z'den benzer kopma modellerine sahip olduğunu, buna karşın karbonik anhidraz II'nin tamamen farklı bir etkileşim profiline sahip olduğunu göstermektedir.
\end{abstract}

\section{Introduction}

Carbonic anhydrases (CAs) are zinc metalloenzymes that play a vital role in various organisms, including humans. This vital role includes many physiological, as well as pathological processes, including lipogenesis, gluconeogenesis, ureagenesis, and tumorigenesis $[1,2]$. There are 16 known isoforms of alpha-CAs which are found in different subcellular locations [1]. Five of them, namely CA I, II, III, VII and XII, function in the cytosol. Human CA I, II, III and VII share approximately $35 \%$ sequence identity and have 
similar structures (Figure 1). The zinc interacting histidines, namely His 64, 94, 96 and 119 (CA II numbering), are conserved across all four of these isoforms. However, small changes in sequence may cause striking differences in enzymatic activity.

Since carbonic anhydrase inhibitors are used as drugs to treat diseases like glaucoma, epilepsy, cancer, and others, finding selective inhibitors targeting a specific CA isoform is an important goal. A number of sulfonamide- and sulfamate-based CA inhibitors have been developed over time [3, 4]. Most of these inhibitors interact with zinc, and they act through effects on the proton transfer mechanism of CAs. In recent years, a new class of inhibitors, called Coumarins, has been the subject of intensive research. Unlike the earlier inhibitors, Coumarins do not interact with zinc and they do not form a covalent bond with CAs [5]. Therefore, they constitute a new class of CA inhibitors with a different mechanism of inhibition. It will be of tremendous benefit to understand, at the molecular level, the precise mechanisms by which Coumarin interacts with CAs, leading to inhibition of enzyme activity. Knowledge of Coumarin's enzyme specificity and a description of its interaction with specific CA amino acid residues could help the development of novel drugs, with better specificity, and less side effects, for the treatment of diseases like glaucoma, epilepsy and cancer $[6,7]$.

The interactions of three Coumarin derivatives (Coumarin1, Coumarin2, and Coumarin3) with various CA isoforms have been reported previously [5]. In that study, the hydrolysis product of Coumarin2 (referred to as Coumarin2 5Z/5E) was shown to have a greater binding affinity for CA I and CA II than Coumarin2 itself. Unfortunately, that study only reported the binding affinity of Coumarin2 5Z/5E for CA I and CA II. Therefore, it is still unknown how Coumarin2 5Z/5E interacts with other cytosolic CAs like CA III and CA VII. Likewise, the molecular details of its interactions with CAs and the precise residues involved in binding remain to be elucidated. For these reasons, the author investigated how Coumarin2 5Z/5E interacts with four human cytosolic (namely CAs I, II, III and VII). Although there are numerous atomic level studies on carbonic anhydrases, most of these have concentrated on the interactions with zinc and the well-described proton transfer mechanism [11-15]. Instead here, the author have focused on describing the atomic interactions of Coumarin2 5Z/5E with four human cytosolic CAs using SMD method.

SMD simulations are similar to single molecule Atomic Force Microscopy (AFM) experiments. These types of experiments can shed light on the interaction of ligands with proteins [16-18]. Atomic scale data of rupture forces, specific residue-ligand interactions, binding/unbinding pathways, ligand recognition
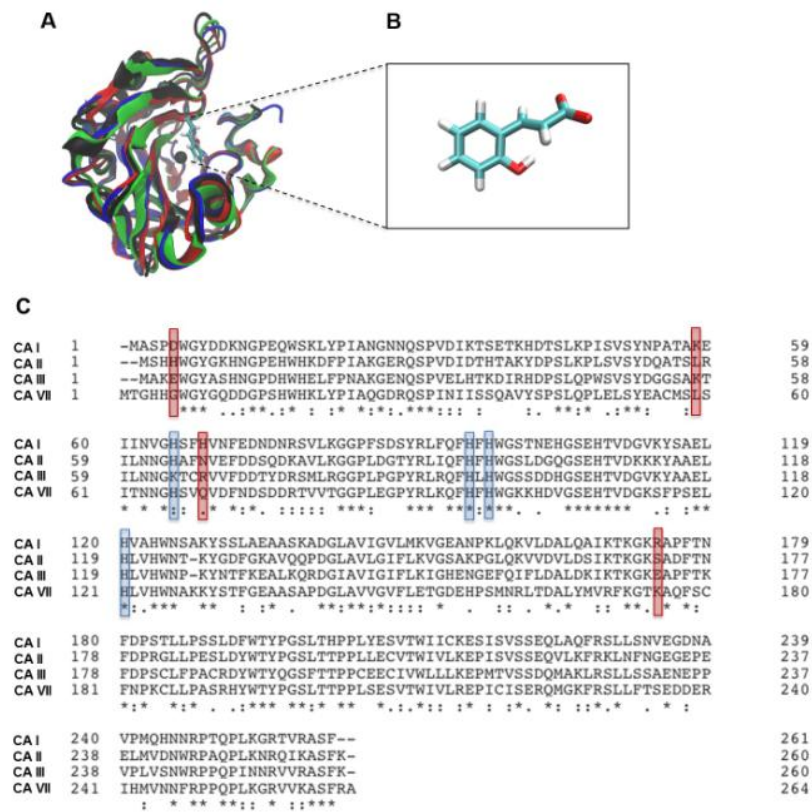

Figure 1. A) Four carbonic anhydrases and Coumarin2 $5 \mathrm{Z} / 5 \mathrm{E}$ were superimposed using the MultiSeq tool in VMD $[8,9]$. The zinc ion is shown as a black sphere in the VdW representation and Coumarin2 $5 \mathrm{Z} / 5 \mathrm{E}$ is represented in licorice. CA I is in black, CA II is red, CA III is in green, and CA VII is in blue. B) Coumarin2 5Z/5E molecule is shown in licorice. C) The amino acid sequence alignment of four human cytosolic carbonic anhydrases were obtained from UniProt [10]. Important histidine residues have been highlighted with transparent blue boxes and residues involved in hydrogen bonds with Coumarin2 5Z/5E are highlighted with red transparent boxes. Under the sequence alignment, star $\left({ }^{*}\right)$ denotes residue identity, colon $(:)$ indicates strong similarity while dot (.) indicates weak similarity of the residues.

residues, as well as the calculated potential of mean force, can all be derived as a result of SMD simulations [19-22]. Due to the tremendous wealth of information it can provide, SMD was used to characterize the interactions of Coumarin2 5Z/5E with four human cytosolic CAs.

In this study, answers of following three questions were sought: Can rupture force be used to quantify the degree of interaction of Coumarin2 5Z/5E with CAs? Is there a possible long-range effect of Coumarin2 $5 \mathrm{Z} / 5 \mathrm{E}$ on the zinc-interacting residue, Histidine 64 , a residue known to be involved in proton transport? Can the residues that play an important role in the binding/unbinding of Coumarin2 5Z/5E be identified?

\section{Material and Method}

The following Protein Databank entries were used for simulations as initial structures: $1 \mathrm{HCB}$ for CA I, 3F8E for CA II, $1 Z 93$ for CA III, and 3MDZ for CA VII [5, 23, 24]. Water molecules in the crystal structures were retained. The systems were solvated with a $10 \AA$ solvent buffer to produce triclinic boxes. $\mathrm{Na}^{+}$and $\mathrm{Cl}^{-}$ counter ions were added at $0.15 \mathrm{M}$ to make the systems neutral. The NAMD program with Charmm27 
force field was used to perform SMD simulations [2527]. The system compositions for all simulations are given in Table $\mathrm{S} 1$.

A previous automated procedure was adopted to determine the atom types of Coumarin2 5Z/5E in the framework of the Charmm General Force Field (CGenFF) 0000[28]. After automated atom type assignment, Coumarin2 5Z/5E was parameterized using the Force Field Tool Kit (FFTK) implemented in VMD [29]. The Gaussian 09 program was used for quantum mechanical calculations in the parameterization procedure [30].

A thorough minimization of 50000 steps was performed after system construction. The systems were heated to $300 \mathrm{~K}$ in $0.001 \mathrm{~K}$ increments and one femtosecond time step was used for all of the simulations. A two-nanosecond equilibration period, under constant pressure (1 atm.) and temperature $(300 \mathrm{~K})$, followed the heating procedure. The Langevin barostat and thermostat were used for pressure and temperature control [31]. Particle Mesh Ewald (PME) method, with a grid spacing of $1.0 \AA$, was used to model electrostatic interactions [32] with the long-range force cutoff distance set to 12.5 $\AA$. The average $C_{\alpha}$ Root Mean Square Deviations (RMSDs) during equilibration were $0.756 \AA$, $0.844 \AA$, $0.851 \AA$ and $0.973 \AA$ for the CA I, II, III and VII crystal structures, respectively. Even though there was not any restriction during equilibration, the RMSD was small and this indicated that the enzymes did not undergo a conformational change during equilibration. Hydrophobic and hydrogen bond interactions of the final frames of the equilibration procedure were plotted using LigPlot+ and the data is shown in Supplementary Information Figure S3 [33].

Similar to AFM experiments, SMD simulations are also mostly single molecule studies. For this reason, a periodic boundary condition was not used during production runs. In production runs, the ligand was removed from the active site cavity for 2.5 nanoseconds along an approximately linear path with a constant velocity of $0.04 \AA / p s$. The production run time was doubled when the pulling velocity was reduced to $0.02 \AA / p s$. VMD program and various custom-made Python scripts were used for analyses [9]. The amino- and carboxy-terminals of all the CAs were fixed to prevent protein drift during ligand pulling and this remained the only applied constraint.

\section{Results}

\subsection{Effect of different force constants on the force-time profile}

Initially, the author wished to explore what effect changing the force constant would have on ForceTime profiles. In order to examine this, CA II was tested with both $\mathrm{k}=500 \mathrm{pN} / \AA$ and $\mathrm{k}=1000 \mathrm{pN} / \AA$ as the spring force constants. The Xmgrace program, using a running average of 25 frames, was used to remove noise from all force related curves (Figure 2). The results show that the Force-Time profiles were relatively insensitive to spring force constant change. However, the stiffer spring force constant $(k=1000$ $\mathrm{pN} / \AA ̊$ ) was selected due to the recommendations in previous studies $[34,35]$.

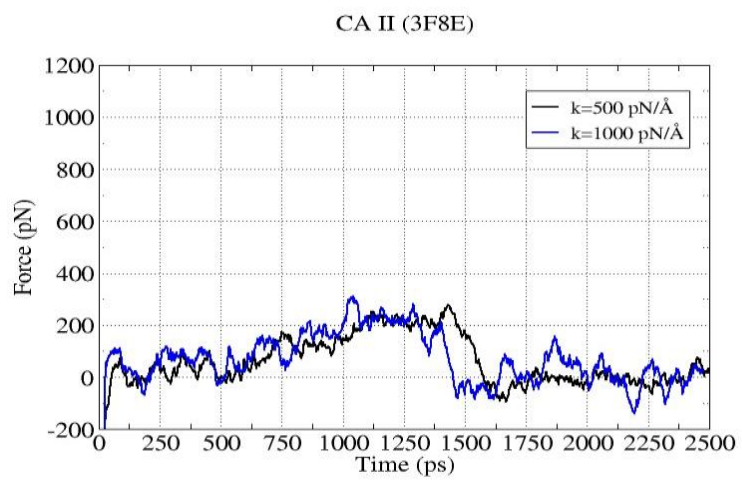

Figure 2. Force-Time profiles for $\mathrm{k}=500 \mathrm{pN} / \AA ̊$ (black) and $\mathrm{k}=1000 \mathrm{pN} / \AA ̊$ (blue) force constants.

\subsection{Force-distance profiles}

Force in the pulling direction was plotted against the distance of the ligand from its initial position for ten trajectories with velocity $v=0.04 \AA / p s$ (Figure 3 ). A peak around $50 \AA$ was found to be present in all of the plots. This peak corresponds to complete dissociation of the ligand from the protein and the solvation shells around it. Snapshots of the first trajectories, with approximately a $50 \AA$ distance between the ligand and the individual CA isozymes, are shown in Figure S4. In a Force-Distance plot, the highest value of force is called the rupture force. The rupture force did not vary significantly between CA I and CA II. On the other hand, in CA III it was found to vary from approximately $523 \mathrm{pN}$ (Trajectory 10) to 1153 pN (Trajectory 9). In CA VII the highest rupture force noted was $838 \mathrm{pN}$ (Trajectory 2) while the lowest was 312 pN (Trajectory 1). The force becomes approximately zero above a protein-ligand distance of $60 \AA$ for all isozymes. A sharp peak around $20 \AA$ was also common in all cytosolic CAs with the exception of CA II.

The selection of a reasonable velocity in constant velocity pulling simulations is an important consideration. Previous studies have shown that varying the pulling velocity does not significantly influence SMD results $[20,36]$. In the majority of cases, reducing the pulling velocity results only in smaller force values. Indeed, qualitatively similar results were observed in this study as well. However, repeating SMD simulations with various velocities to ensure qualitative similarity of the results is a common practice $[16,36]$. For this reason, all of the simulations were repeated with $v=0.02 \AA / p s$ velocity. The data of Force-Distance profiles is given in Figure 4. 


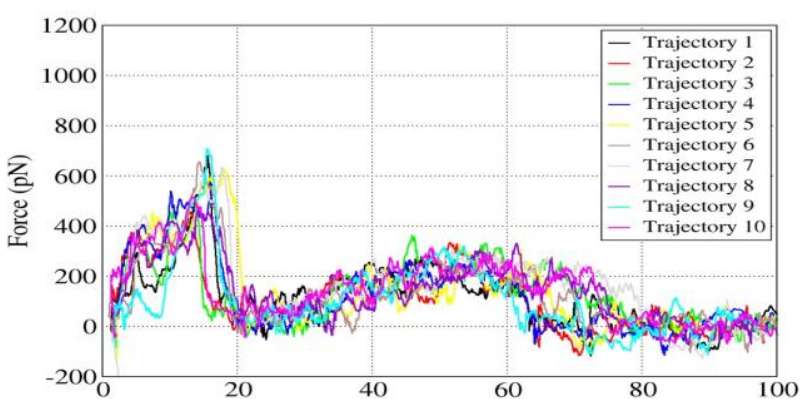

C

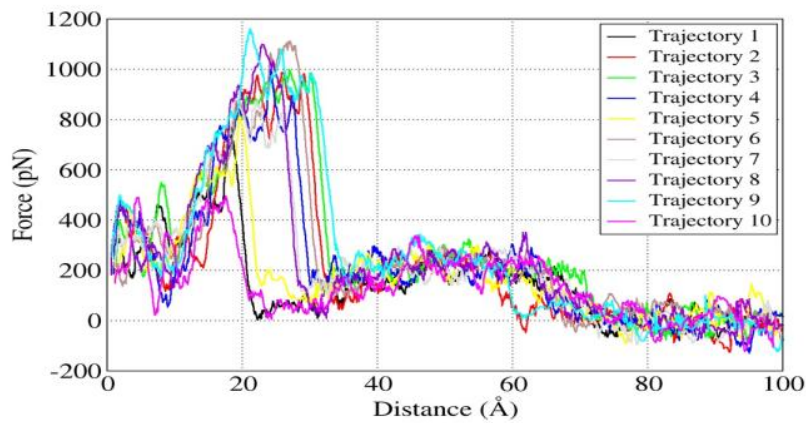

B

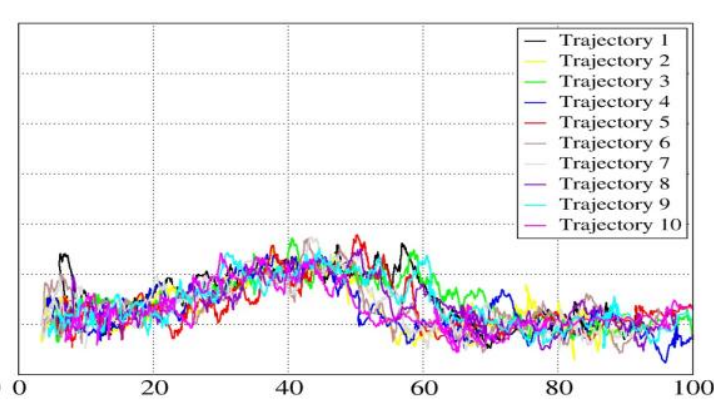

$\mathrm{D}$

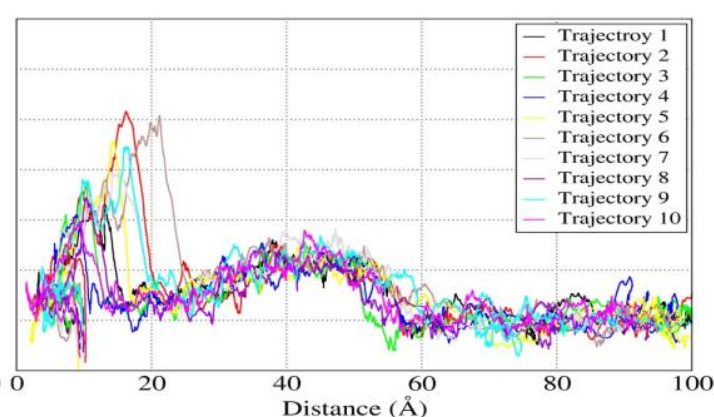

Figure 3. Force-Distance profiles for velocity=0.04 ̊̊/ps A) CA I, B) CA II, C) CA III, D) CA VII.
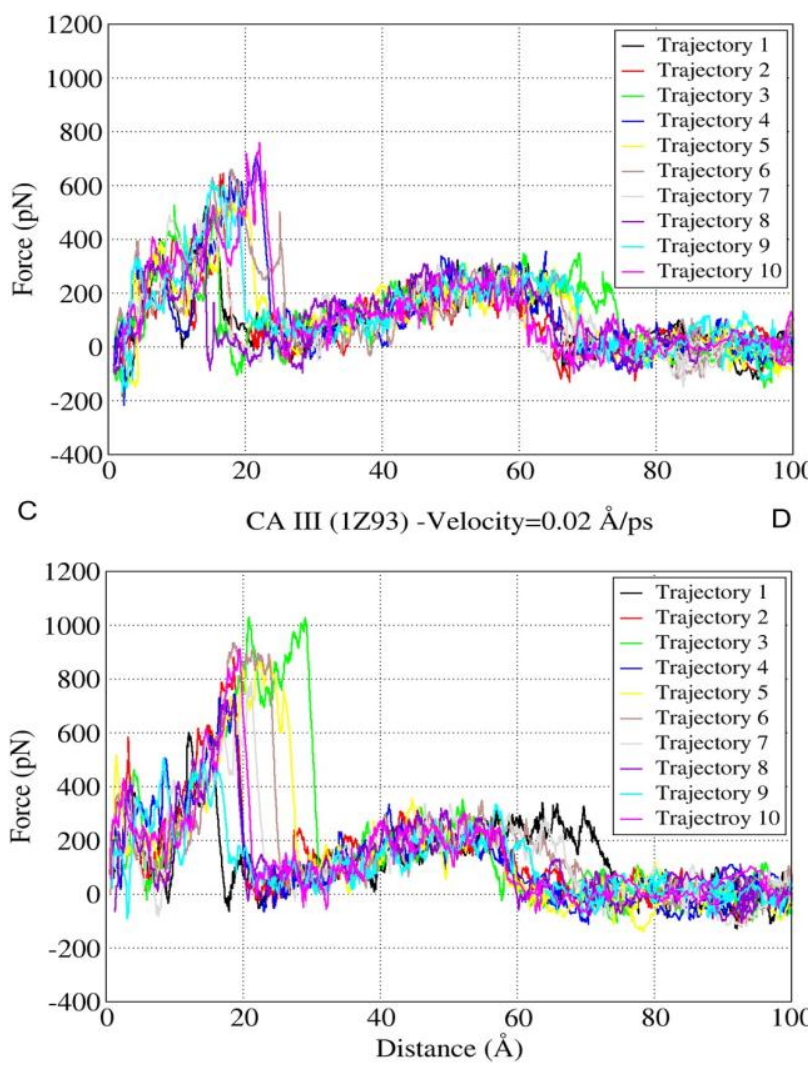

B

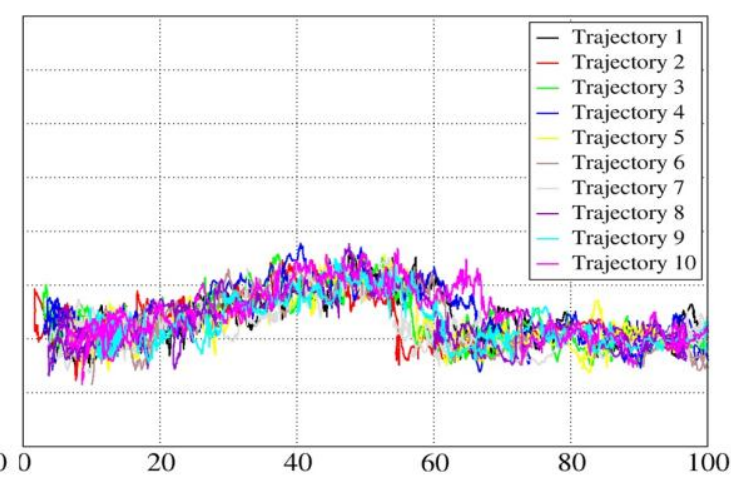

CA VII (3MDZ) - Velocity $=0.02 \AA / p s$

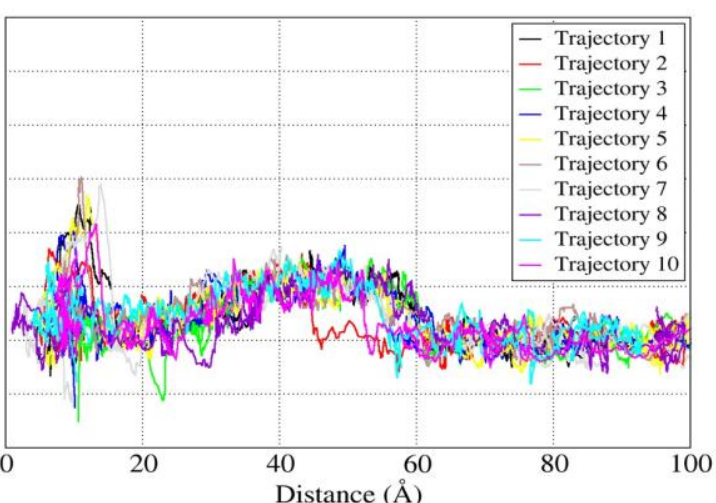

Figure 4. Force-Distance profiles for velocity $=0.02 \AA$ As A) CA I, B) CA II, C) CA III, D) CA VII.

As expected, and discussed above, the force decreased slightly in the slower simulations for almost all CA trajectories. Similar to the $0.04 \AA / p s$ simulations, there was significantly more variation in force in the CA III simulations. Despite these differences, in general the shapes of all SMD simulations were similar regardless of the pulling velocity. As a result, the insensitivity of the data to the pulling velocity shows that the data is robust. 

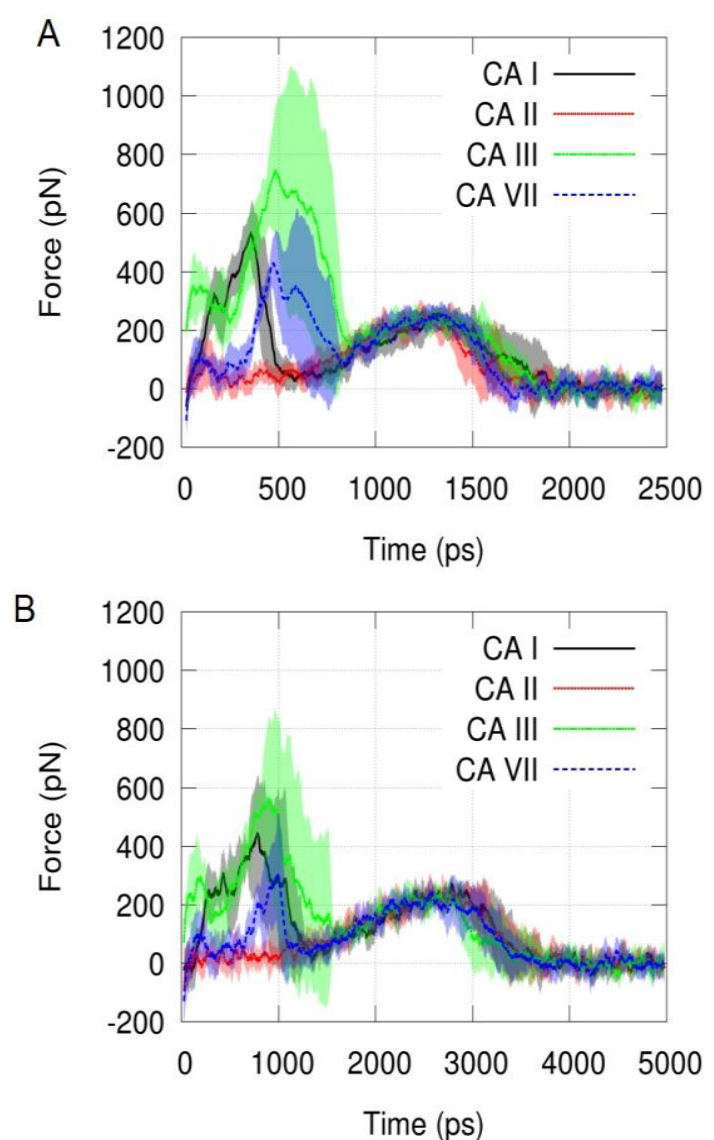

Figure 5. Average forces (lines) and their standard deviations (shades) for all simulations. A) Velocity $=0.04$ $\AA$ A/ps simulations B) Velocity $=0.02 \AA$ /ps simulations.

The average forces and their standard deviations were plotted with respect to simulation time for all systems and the data is presented in Figure 5. The data clearly show that, although simulation times vary, the average force profiles are preserved for both the slow and the fast simulations. The average rupture force for CA III is about $700 \mathrm{pN}$ at $0.04 \AA / \mathrm{ps}$ and it decreases to $600 \mathrm{pN}$ when the pulling velocity is reduced to $0.02 \AA / p s$. The average rupture force of CA I is $500 \mathrm{pN}$ for the faster simulation and it decreases to about $100 \mathrm{pN}$ in the slower simulation. For CA VII, the average rupture force is $400 \mathrm{pN}$ at $0.04 \AA / p s$ pulling velocity and it falls to approximately $300 \mathrm{pN}$ when the pulling velocity is reduced to $0.02 \AA / p s$. Interestingly, CA II has a distinct profile when compared with the other three CAs. The height of the force peak was not as sensitive to pulling velocity as was observed for the other CAs. It should also be noted that standard deviations are higher in the simulations for CA III and CA VII compared to CA I and II. The unprocessed Force-Time curves are presented in Supplementary Information Figure S1 and S2.

\subsection{Position of histidine 64 (His 64)}

His 64 (based on CA II residue numbering) plays an important role in the proton transfer mechanism of many CAs, and many sulfonamide- and sulfamate- based CA inhibitors interact with this residue. Because of its importance, His 64 positions in CA II have been the subject of computational and experimental studies $[11,15]$. Based on the distance of ND1 atom of His 64 residue and $\mathrm{Zn}$ atom, His 64 has two conformations: namely "in" and "out" conformations. The author wondered whether Coumarin2 5Z/5E could cause any conformational change in the His 64 residue during the unbinding process (Figure 6). Since CA III does not have a corresponding Histidine (see Figure 1-C sequence alignment), it was excluded from this analysis. The data show that CA I has the greatest ND1-Zn distance. It turns to the "in" conformation in only two trajectories (Trajectory 4 and 6). Since this conformational change occurs before rupture of the ligand from the protein, it is not correlated with ligand unbinding. His64 in CA II demonstrate "out" conformations at approximately $8 \AA$ distance and frequent jumps to the "in" conformation are observed. In contrast, although CA VII "out" conformations have distances similar to CA II, similar jumps to an "in" conformation were not observed. Based on these observations, which do not demonstrate a concerted His64 conformational change with Coumarin2 5Z/5E unbinding, the conclusion is that Coumarins interact with CAs in a manner distinct from sulfonamide- and sulfamatebased inhibitors.

\subsection{Hydrogen bonds between Coumarin2 5Z/5E and CA isozymes}

Hydrogen bonds formed between Coumarin2 5Z/5E and all of the CA isozymes were investigated during the simulation (Figure 7). A consistent hydrogen bond between Coumarin2 5Z/5E and Lys 58 of CA I was observed in the first half nanosecond. A shortlived hydrogen bond between the ligand and His 4 was noted for CA II; this bond had the shortest lifetime compared to other hydrogen bonds noted. Coumarin2 5Z/5E also formed a hydrogen bond with Arg 67 of CA III and, in contrast with the CA II His 4 bond, this hydrogen bond was the most stable of the three hydrogen bonds Coumarin 2 2Z/5E formed with CA III. In fact, the lifetime of this hydrogen bond interaction extended up to 750 ps and it was the most persistent hydrogen bond noted among the four isozyme simulations. Lys 175 of CA VII also formed a hydrogen bond with Coumarin 2 ZZ/5E and the lifetime of this bond was comparable with the hydrogen bond of Arg 67 in CA III. However, CA VII Lys 175 formed only one bond with Coumarin2 5Z/5E. These data are perhaps not surprising since hydrogen bonding residues are not conserved across the different isozymes (see Figure 1-C). Additionally, one can clearly see that the difference between the hydrogen bonding patterns of Coumarin2 5Z/5E across isozyme may explain why there is a peak around $20 \AA$ in CA I, III, VII and why this peak is not observed in CA II. 
A

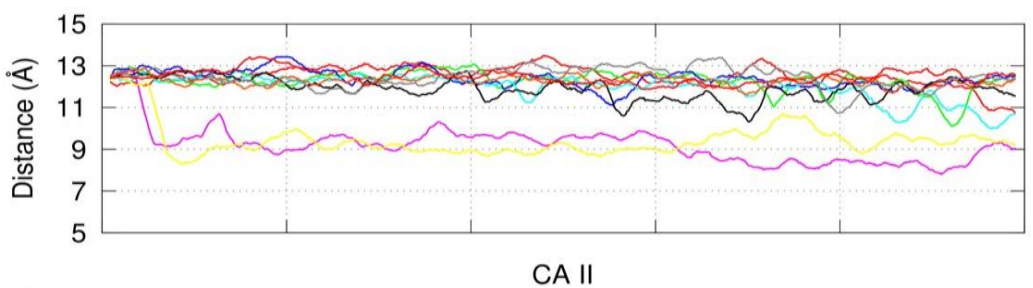

B

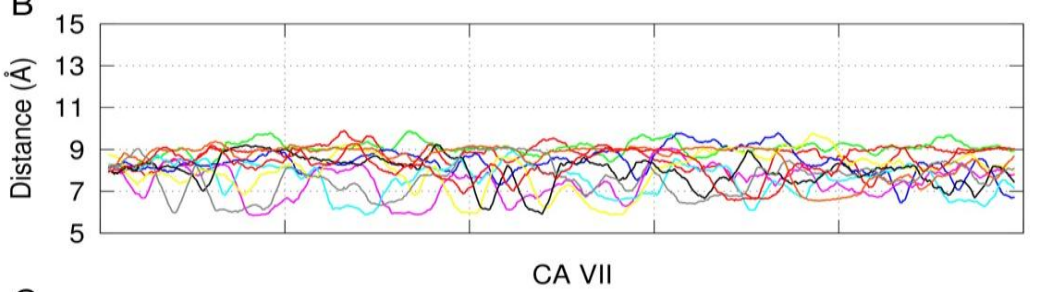

C

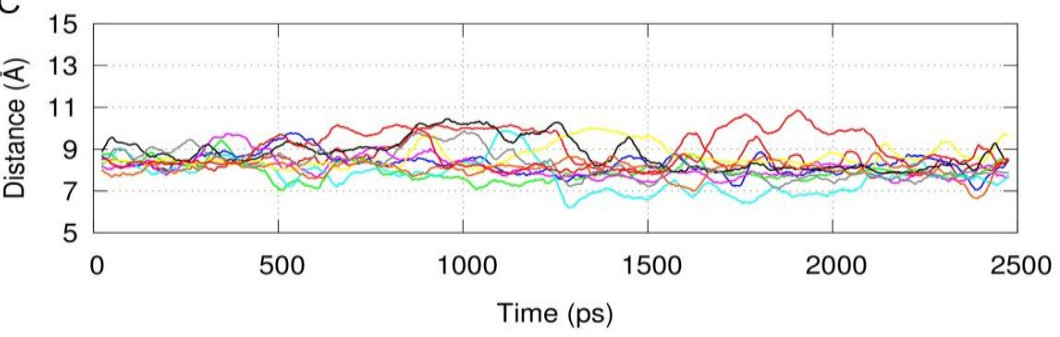

Trajectory 1

Trajectory 2

Trajectory 3

Trajectory 4

Trajectory 5

Trajectory 6

Trajectory 7

Trajectory 8

Trajectory 9

Trajectory 10

Figure 6. Histidine 64 positions in A) CA I, B) CA II, and C) CA VII.
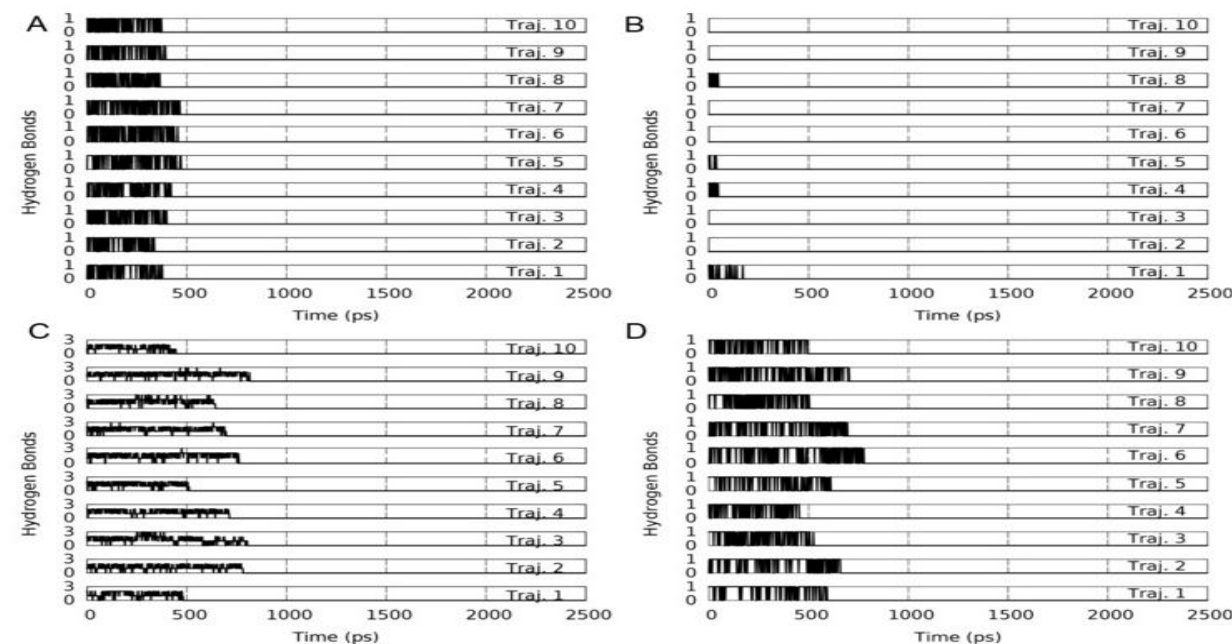

D

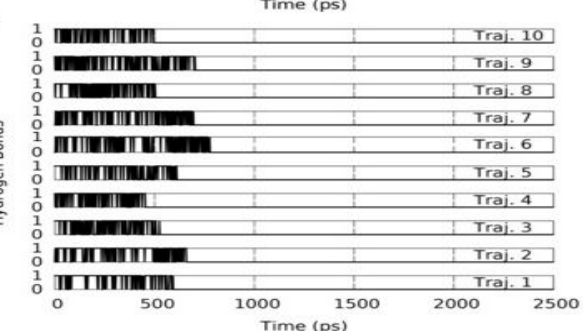

Figure 7. Hydrogen bonds between CAs and Coumarin2 5Z/5E A) CA I-Lys 58 B) CA II-His 4 C) CA III-Arg 67 D) CA VII-Lys 175.

\section{Discussion and Conclusion}

In this study, 40 ligand-unbinding SMD simulations for four human cytosolic CAs were performed. Each enzyme showed a different pattern of interactions with the ligand Coumarin2 5Z/5E. The order of rupture force is CA $\mathrm{III}>\mathrm{CA}$ I $>\mathrm{CA}$ VII $>$ CA II. Previously published data has shown that Coumarin2 5Z/5E has a lower binding affinity for CA I than CA II [5]. These SMD simulations also confirm this fact qualitatively. Correlation between rupture forces and experimental binding affinities have been studied [22] and have shown that a higher rupture force is correlated with a lower binding affinity. Based on this correlation, one can predict that CA III will have the lowest binding affinity and CA II will have the highest binding affinity for Coumarin2 5Z/5E. Compared to the other CAs, CA II demonstrates the least ligand interactions. Long range interactions such as electrostatic and Van der Waals forces are predominant in the interactions of CA II with Coumarin2 5Z/5E. In contrast, CA III interacts strongly with Coumarin2 5Z/5E whereas the interactions of ligand with CA VII and CA I are intermediate between CA III and CA II.

These results also highlight both the important residues involved in Coumarin2 5Z/5E interactions, as well as differences in residue interaction across isozymes. Lys 58 in CA I, His 4 in CA II, Arg 67 in CA III and Lys 175 in CA VII are all important residues involved in interactions with Coumarin2 5Z/5E. 
Mutations of these residues will significantly disrupt Coumarin2 5Z/5E inhibition. This new information can now be used to aid in designing a new generation of carbonic anhydrase inhibitors that could lead to new drugs for the treatment of glaucoma, epilepsy, cancer and other diseases. The data in this paper also confirm that, since there is no concerted motion between His 64 conformations and Coumarin2 $5 \mathrm{Z} / 5 \mathrm{E}$, the mechanism of Coumarin inhibition is not through a zinc interaction or a proton transfer mechanism.

In summary, the SMD simulation of cytosolic CAs has successfully led to predictions regarding the relative affinity and binding mode of Coumrain2 5Z/5E to these enzymes. Although SMD can't give experimental unbinding energies, it is still a very useful computational method to characterize possible ligand-protein interactions as well as average rupture forces of ligands, which are known to be correlated with experimental binding affinities as shown previously [22].

\section{Acknowledgment}

The numerical calculations reported in this paper were performed at TUBITAK ULAKBIM, High Performance and Grid Computing Center (TRUBA Resources). I thank them for providing us superb computational resources and technical help for this research. Moreover, I thank Dr. Murat Aycibin for his grammatical check and critical reading. This project has been supported by TUBITAK (Turkish Scientific and Technical Research Institute) under project number $114 \mathrm{Z} 045$.

\section{References}

[1] Supuran, C. T. 2008. Carbonic anhydrases--an overview. Current Pharmaceutical Design, 14(7), 603-14.

[2] Supuran, C. T. 2008. Carbonic anhydrases: novel therapeutic applications for inhibitors and activators. Nature Reviews Drug Discovery, 7(2), 168-81.

[3] Supuran, C. T. 2010. Carbonic anhydrase inhibitors. Bioorganic \& Medicinal Chemistry Letters, 20(12), 3467-74.

[4] Carta, F., Supuran, C. T., Scozzafava, A. 2014. Sulfonamides and their isosters as carbonic anhydrase inhibitors. Future Medicinal Chemistry, 6(10), 1149-65.

[5] Maresca, A., Temperini, C., Vu, H., Pham, N. B., Poulsen, S. A., et al. 2009. Non-zinc mediated inhibition of carbonic anhydrases: coumarins are a new class of suicide inhibitors. Journal of American Chemical Society, 131(8), 3057-62.

[6] Maren, T. H. 1987. Carbonic-Anhydrase - General Perspectives and Advances in Glaucoma
Research. Drug Development Research, 10(4), 255-76.

[7] Thiry, A., Dogne, J., Supuran, C. T., Masereel, B. 2007. Carbonic anhydrase inhibitors as anticonvulsant agents. Current Topics in Medicinal Chemistry, 7(9), 855-64.

[8] Roberts, E., Eargle, J., Wright, D., LutheySchulten, Z. 2006. MultiSeq: unifying sequence and structure data for evolutionary analysis. BMC Bioinformatics, 7, 382.

[9] Humphrey, W., Dalke, A., Schulten, K. 1996. VMD: visual molecular dynamics. Journal of Molecular Graphics and Modelling, 14(1), 33-8, 27-8.

[10] UniProt, Consortium. 2015. UniProt: a hub for protein information. Nucleic Acids Research, 43(Database issue), 204-12.

[11] Lu, D., Voth, G. A. 1998. Molecular dynamics simulations of human carbonic anhydrase II: insight into experimental results and the role of solvation. Proteins, 33(1), 119-34.

[12] Toba, S., Colombo, G., Merz, K. M. 1999. Solvent dynamics and mechanism of proton transfer in human carbonic anhydrase II. Journal of American Chemical Society, 121(10), 2290-302.

[13] Ohta, S., Alam, M. T., Arakawa, H., Ikai, A. 2004. Origin of mechanical strength of bovine carbonic anhydrase studied by molecular dynamics simulation. Biophysical Journal, 87(6), 4007-20.

[14] Fisher, S. Z., Maupin, C. M., Budayova-Spano, M., Govindasamy, L., Tu, C., et al. 2007. Atomic crystal and molecular dynamics simulation structures of human carbonic anhydrase II: insights into the proton transfer mechanism. Biochemistry, 46(11), 2930-7.

[15] Maupin, C. M., Voth, G. A. 2007. Preferred orientations of His64 in human carbonic anhydrase II. Biochemistry, 46(11), 2938-47.

[16] Grubmuller, H., Heymann, B., Tavan, P. 1996. Ligand binding: Molecular mechanics calculation of the streptavidin biotin rupture force. Science, 271(5251), 997-9.

[17] Izrailev, S., Stepaniants, S., Balsera, M., Oono, Y., Schulten, K. 1997. Molecular dynamics study of unbinding of the avidin-biotin complex. Biophysical Journal, 72(4), 1568-81.

[18] Xu, Y. C., Shen, J. H., Luo, X. M., Shen, X., Chen, K. X., et al. 2004. Steered molecular dynamics simulations of protein-ligand interactions. Science in China Series B, 47(5), 355-66.

[19] Kosztin, D., Izrailev, S., Schulten, K. 1999. Unbinding of retinoic acid from its receptor studied by steered molecular dynamics. Biophysical Journal, 76(1), 188-97. 
[20] Shen, L., Shen, J., Luo, X., Cheng, F., Xu, Y., et al. 2003. Steered molecular dynamics simulation on the binding of NNRTI to HIV-1 RT. Biophysical Journal, 84(6), 3547-63.

[21] Martinez, L., Webb, P., Polikarpov, I., Skaf, M. S. 2006. Molecular dynamics simulations of ligand dissociation from thyroid hormone receptors: Evidence of the likeliest escape pathway and its implications for the design of novel ligands. Journal of Medicinal Chemistry, 49(1), 23-6.

[22] Mai, B. K., Li, M. S. 2011. Neuraminidase inhibitor R-125489-A promising drug for treating influenza virus: Steered molecular dynamics approach. Biochemical and Biophysical Research Communications, 410(3), 688-91.

[23] Kumar, V., Kannan, K. K. 1994. Enzyme-substrate interactions. Structure of human carbonic anhydrase I complexed with bicarbonate. Journal of Molecular Biology, 241(2), 226-32.

[24] Duda, D. M., Tu, C., Fisher, S. Z., An, H., Yoshioka, C., et al. 2005. Human carbonic anhydrase III: structural and kinetic study of catalysis and proton transfer. Biochemistry, 44(30), 1004653.

[25] Phillips, J. C., Braun, R., Wang, W., Gumbart, J., Tajkhorshid, E., et al. 2005. Scalable molecular dynamics with NAMD. Journal of Computational Chemistry, 26(16), 1781-802.

[26] MacKerell, A. D., Brooks, C. L., Nilsson, L., Roux, B., Won, Y., et al. 1998. CHARMM: The Energy Function and Its Parameterization with an Overview of the Program. Encyclopedia of Computational Chemistry. John Wiley \& Sons, Chichester, 271-277.

[27] MacKerell, A. D., Jr., Banavali, N., Foloppe, N. 2000. Development and current status of the CHARMM force field for nucleic acids. Biopolymers, 56(4), 257-65.
[28] Vanommeslaeghe, K., Hatcher, E., Acharya, C., Kundu, S., Zhong, S., et al. 2010. CHARMM general force field: A force field for drug-like molecules compatible with the CHARMM allatom additive biological force fields. Journal of Computational Chemistry, 31(4), 671-90.

[29] Mayne, C. G., Saam, J., Schulten, K., Tajkhorshid, E., Gumbart, J. C. 2013. Rapid parameterization of small molecules using the Force Field Toolkit. Journal of Computational Chemistry, 34(32), 2757-70.

[30] Frisch, Michael J., Trucks, G. W., Schlegel, H. Bernhard, Scuseria, Gustavo E., Robb, Michael A., et al. 2009. Gaussian, 09.

[31] Loncharich, R. J., Brooks, B. R., Pastor, R. W. 1992. Langevin dynamics of peptides: the frictional dependence of isomerization rates of $\mathrm{N}$-acetylalanyl-N'-methylamide. Biopolymers, 32(5), 523-35.

[32] Darden, T., York, D., Pedersen, L. 1993. Particle Mesh Ewald - an N.Log(N) Method for Ewald Sums in Large Systems. Journal of Chemical Physics, 98(12), 10089-92.

[33] Laskowski, R. A., Swindells, M. B. 2011. LigPlot+: multiple ligand-protein interaction diagrams for drug discovery. Journal Chemical Information and Modelling, 51(10), 2778-86.

[34] Park, S., Khalili-Araghi, F., Tajkhorshid, E., Schulten, K. 2003. Free energy calculation from steered molecular dynamics simulations using Jarzynski's equality. Journal of Chemical Physics, 119(6), 3559-66.

[35] Park, S., Schulten, K. 2004. Calculating potentials of mean force from steered molecular dynamics simulations. Journal of Chemical Physics, 120(13), 5946-61.

[36] Heymann, B., Grubmuller, H. 1999. AN02/DNPhapten unbinding forces studied by molecular dynamics atomic force microscopy simulations. Chemical Physics Letters, 303(1-2), 1-9. 


\section{Appendices}

\section{Appendix A. Supplementary Information}

This supplementary information contains 4 figures and 1 table. Table A1 is behind the figures, at the last page of this document.

A

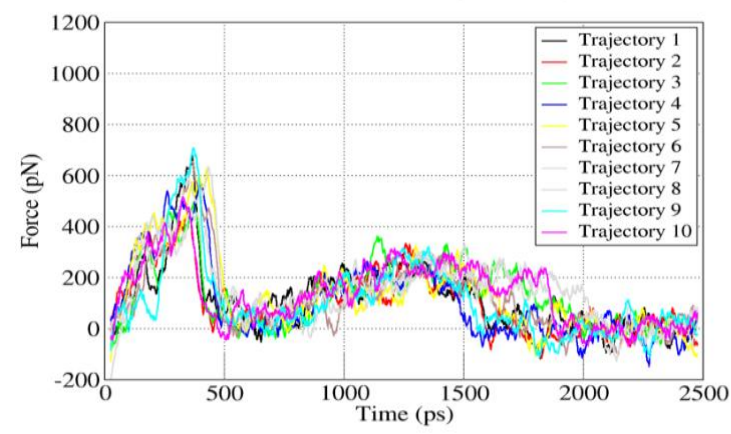

C

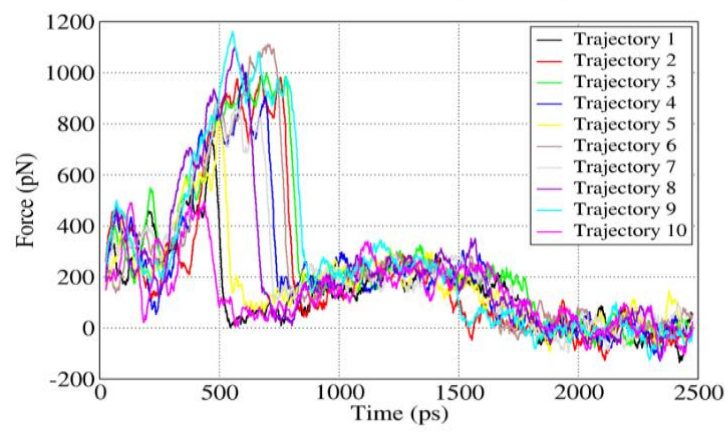

B

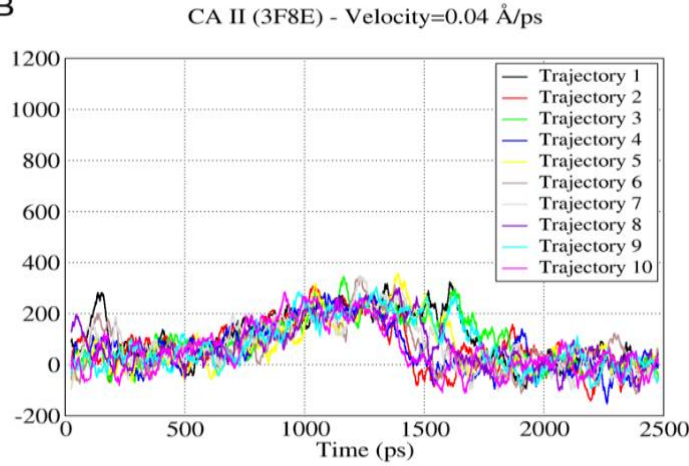

D

CA VII (3MDZ) - Velocity $=0.04 \AA ̊ / p s$

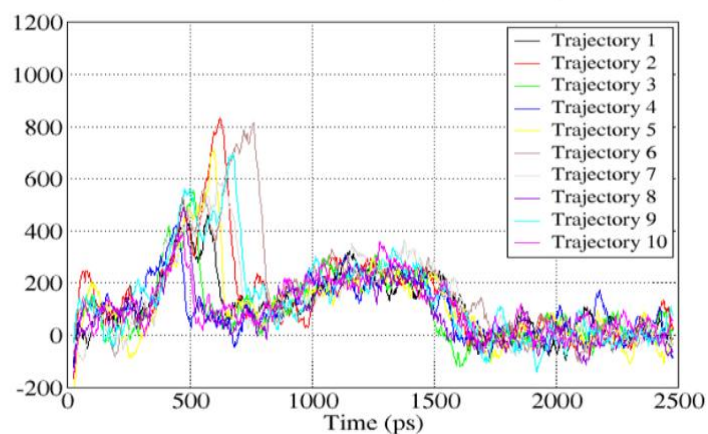

Figure A1. Force-Time curves for $0.04 \AA ̊$ /ps simulations. A) CA I B) CA II C) CA III D) CA VII

A

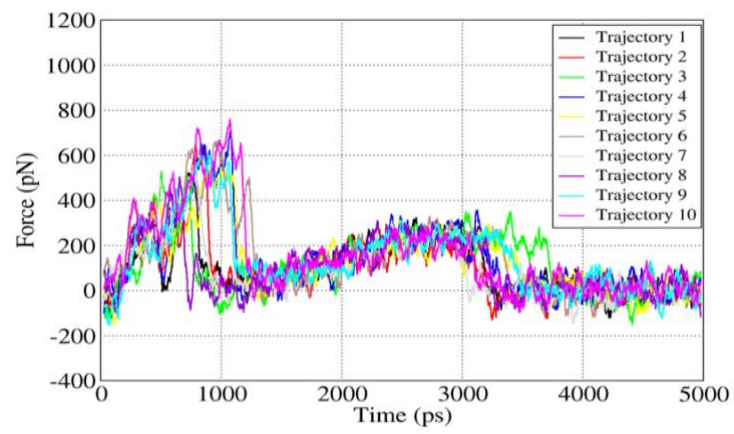

C

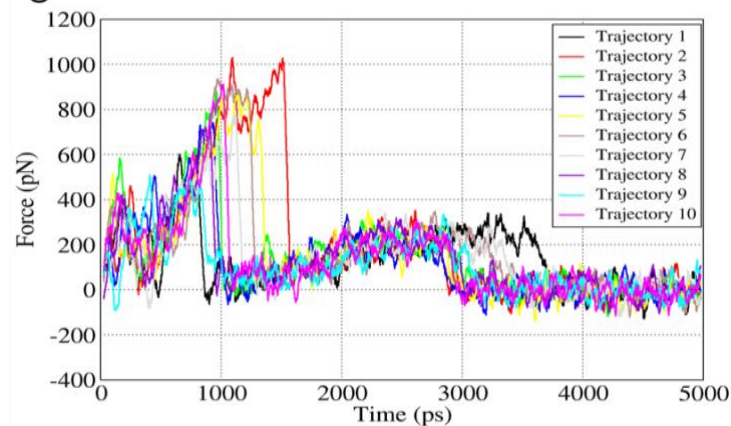

B

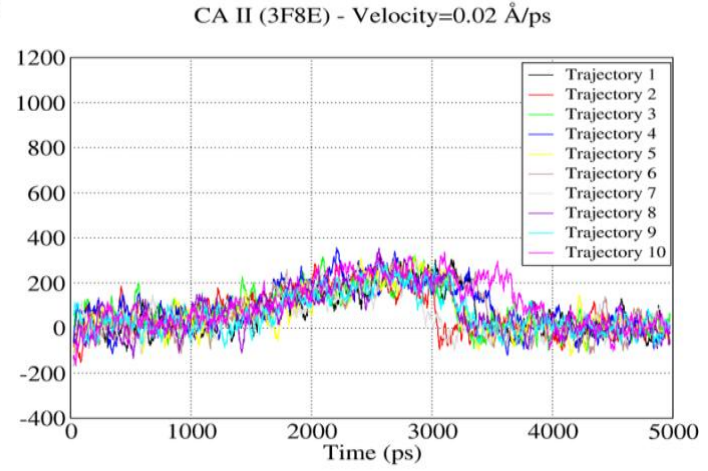

D

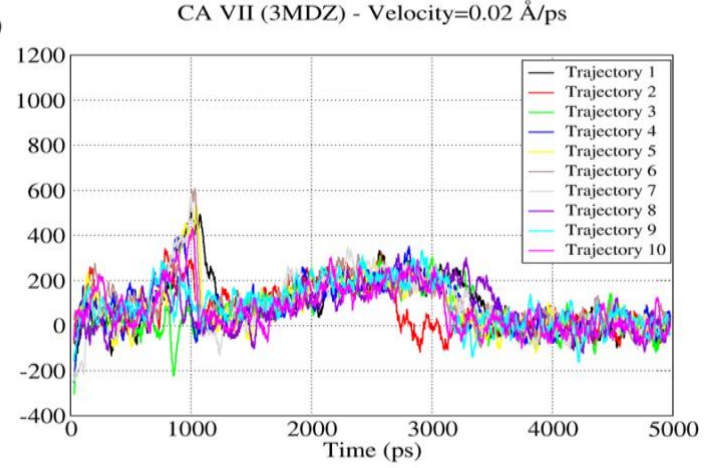

Figure A2. Force-Time curves for $0.04 \AA$ /ps simulations. A) CA I B) CA II C) CA III D) CA VII 


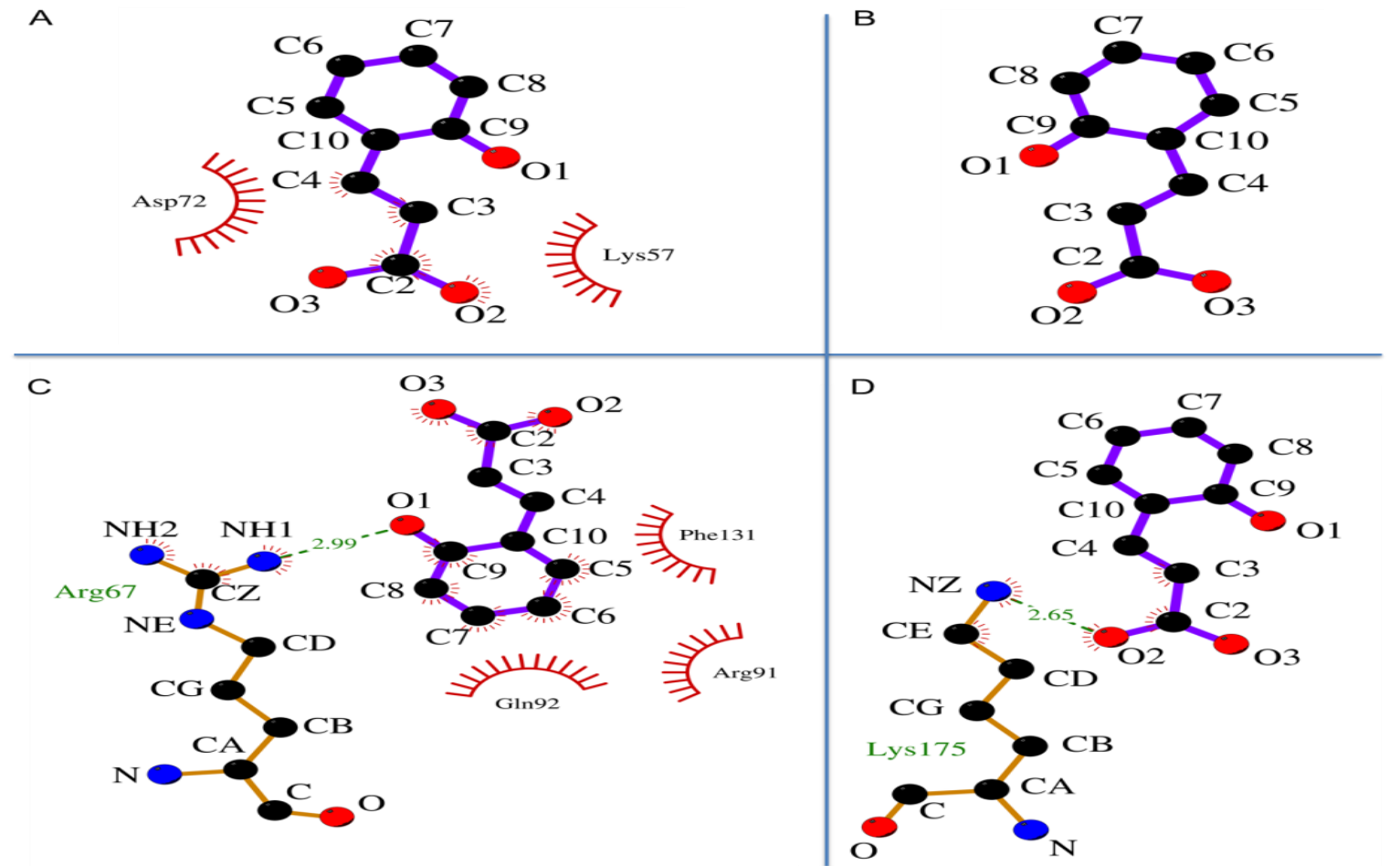

Figure A3. Coumarin2 5Z/5E interactions when production simulations started for A) CA I, B) CA II, C) CA III and D) CA VII

A

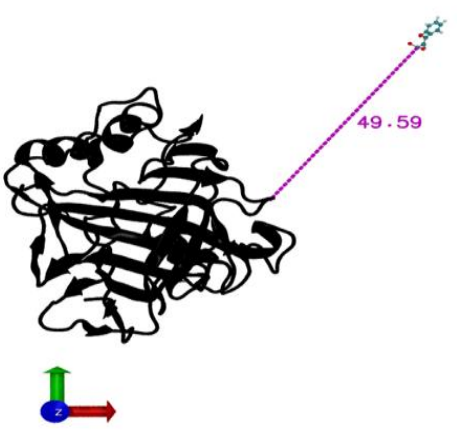

C
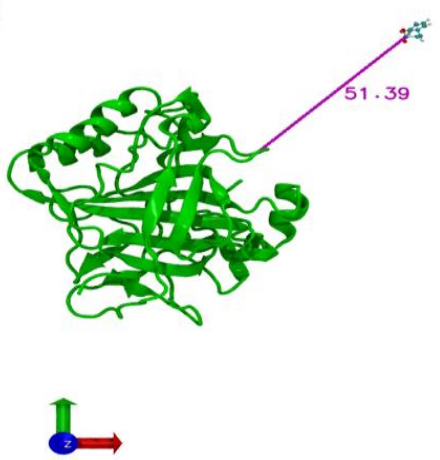

B

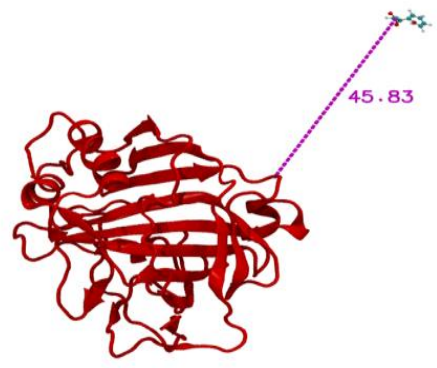

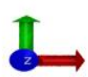

D

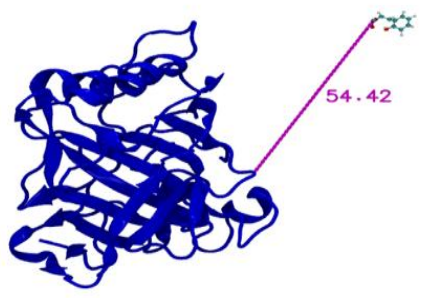

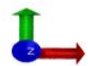

Figure A4. Snapshots of protein and ligand halfway through simulations. Distance unit is Å. A) CA I B) CA II C) CA III D) CA VII

Table A1. System compositions for all simulations

\begin{tabular}{lllllll}
\hline Enzyme & $\begin{array}{l}\text { \# of Protein } \\
\text { Atoms }\end{array}$ & $\begin{array}{l}\text { \# of Water } \\
\text { Molecules }\end{array}$ & $\begin{array}{l}\text { \#of } \mathbf{N a}^{+} \\
\text {Ions }\end{array}$ & \# of Cl- Ions & $\begin{array}{l}\text { \# of Ligand } \\
\text { Atoms+Zn }\end{array}$ & $\begin{array}{l}\text { Total } \\
\text { \# of Atoms }\end{array}$ \\
\hline CA I & 3972 & 11031 & 32 & 31 & 20 & 37148 \\
CA II & 4032 & 9176 & 27 & 26 & 20 & 31633 \\
CA III & 4058 & 9847 & 29 & 28 & 20 & 33676 \\
CA VII & 4032 & 9541 & 28 & 27 & 20 & 32730 \\
\hline
\end{tabular}

